\title{
Depression, Anxiety, Stress among College Students in Bagalkot:
}

\section{A College Based Study}

\author{
Narayan R Mutalik ${ }^{1}$, Shankar Moni ${ }^{2}$, S B Choudhari ${ }^{3}$, Govind S Bhogale ${ }^{4}$
}

\section{ABSTRACT}

Background: Psychological distress such as stress, anxiety and depression are frequent among students which can affect their academic performance, physical health and psychosocial wellbeing. Objective: Aim was to assess the symptoms of depression, anxiety, stress among undergraduate students studying in a govt. degree college, Bagalkot. A total of 133 undergraduate students from Govt. First Grade Colloge, Bagalkot, were included based on universal sampling method. Questionnaires based study was conducted using the Depression Anxiety, Stress Scale (DASS-21) and General health questionnaire (GHQ-28) for assessing the severity of Depression, Anxiety, Stress and emotional distress among students respectively. Result: Level of anxiety was more than depression followed by stress based on DASS 21. It has a high internal consistency and a useful instrument to measure the psychological wellbeing of degree students in Bagalkot. Based on GHQ, females had significant emotional distress as compared to males. Conclusion: Results indicate high grade of depression, anxiety and stress among undergraduate students. This indicates the amount of burden students have to bear in current scenario. Early interventions are needed to improve the quality of life and reduce the stress among student.

Keywords: Psychological Stress, Depression, Anxiety, Mental Health, Students.

Higher education is a stressful period in students' life which they need to cope with due to various reasons as living away from the families, a heavy syllabus, and inefficiency in higher education programs.[1] A mentally fit student can initiate proper social relationships, enthusiastic to learn with ambition to implement his/her plans in the future. Students are at a crucial stage of development as they are more subjected to experience mental illnesses.[2]

\footnotetext{
${ }^{1}$ M.D., Assistant Professor, Department of Psychiatry, S.N.Medical College, Bagalkot, India

${ }^{2}$ Clinical Psychologist, Department of Psychiatry, S.N.Medical College, Bagalkot, India

${ }^{3}$ M.D., Professor, Department of Psychiatry, SNMC , Bagalkot, India

${ }^{4}$ M.D., Professor, Department of Psychiatry, SNMC , Bagalkot, India

*Responding Author

(C) 2016, N Mutalik, S Moni, S Choudhari, G Bhogale; licensee IJIP. This is an Open Access Research distributed under the terms of the Creative Commons Attribution License (http://creativecommons.org/licenses/by/2.0), which permits unrestricted use, distribution, and reproduction in any Medium, provided the original work is properly cited.
} 


\section{Depression, Anxiety, Stress among College Students in Bagalkot: A College Based Study}

Depression and anxiety are common, serious and debilitating mental health problems and are afflicting adolescents and student population to a large extent.[3,4]

World Health Organization (WHO) considered mental health as an important component of human health.[5] Although the onset of depression can be at any stage of life, the prevalence of major depression is increasing during adolescence and young adulthood.[6]

Stress and anxiety during education causes impairment in cognition[7] and produces distortions of perception. As college students are subjected to various stressors such as academic, social or time management problems, it is necessary for the educators and mental health providers to have interventions to reduce anxiety and improve the quality of mental health education.[8]

Studies have noted depression among college students as a risk factor for impaired scholastic performance. Studies report that stress related disorders are under diagnosed which can lead to higher chance of psychiatric disorders which will have serious effects on their careers and social life.[9,10]

As per earlier studies, lifetime prevalence increases from $1 \%$ of the population less than age of 12 years to $17-25 \%$ of the population in late adolescence, with an increase in cases between 1518 years.[11,12] Psychosocial functioning is an important mental health aspect to assess because adolescents spend their most of the time in school.[13]

The adverse effect of psychological distress among students reduces their self-esteem which might cause many problems at both personal and professional levels leading to college dropout, impaired ability to work effectively, poor academic, disturbed relationship and suicide.[14]

Depression, Anxiety, and Stress Scale 21 (DASS-21) and GHQ-28 have been used to assess effect of depression, anxiety, and stress among different population, age-groups and to discriminate between anxiety and depression.

The 28-item General Health Questionnaire (GHQ-28) is a measure of current mental health. Its focus is on the inability to perform normal daily functions and the occurence of distress. It has been widely used in various countries for assessing psychological morbidity. [15,16,17]

No previous studies have been conducted in Bagalkot and none of the previous studies have included studies mentioning regarding prevalence and presence of co-morbid anxiety, depression, interpersonal relations, social life, psychological and physical health. Taking into consideration all these factors it becomes an interesting avenue to explore the prevalence as well as the possible implications of Depression, Anxiety and Stress among undergraduate degree students in Bagalkot.

(C) The International Journal of Indian Psychology, ISSN 2348-5396 (e)| ISSN: 2349-3429 (p) | 180 
Depression, Anxiety, Stress among College Students in Bagalkot: A College Based Study

Aim:

- To assess the symptoms of depression, anxiety, stress among undergraduate students studying in a govt. degree college, Bagalkot.

METHODOLOGY

Design of the Study:

Study design: College based - Cross sectional study.

Study group: Degree college students - Govt. First Grade College, Bagalkot.

Study period: May 2016

\section{Sample Size and Its Calculation:}

All eligible undergraduate students including B.A, B.Sc,

B.Com according to inclusion criteria are taken based on -

Sample size was calculated using open Epi software 2.3.1

At $46 \%$ of prevalence of severe depression. (Based on pilot study)

9\% Absolute precision \& 95\% Confidence Level

Sample size calculated: 118

\section{Inclusion Criteria}

1. $\quad$ Age between 18-25yrs.

2. Students in Govt First grade college.

3. Those who give written informed consent.

\section{Exclusion Criteria}

1. Not giving informed consent.

B. PARAMETERS STUDIED AND TECHNIQUES TO BE EMPLOYED:

Ethical clearance was obtained from the Institute's Ethics Committee (Human Studies). Written informed consent (English) was taken from all study subjects, before enrolment in the study.

\section{Collection of Samples}

The nature and the purpose of the study was explained briefly to the study population in the informed consent form and then the study population were recruited according to inclusionexclusion criteria based on universal sampling. Then, specially constructed semi structured Proforma was given to the study population which aided in collecting socio-demographic details and collecting various study parameters. Standardized scales as below, which were self administrable, were handed over to the sample population.

\section{Depression, Anxiety and Stress Scale (DASS 21):}

It is a self- rated questionnaire which assesses the severity of the symptoms of depression, anxiety and stress. It contains statements referring to the past week. Each item is rated on a 4point scale (Did not apply to me at all means score of 0 , Applied to me very much or most of the time means score of 3). Subjects are asked to circle a 0-3 number indicating how much each 
statement applied to him/her in the last week. Scores for depression, anxiety and stress are calculated by adding the scores for the relevant items. Each subscale is divided into normal, mild, moderate, severe and extremely severe as in table 1.[18]

\section{General Health Questionnaire 28 (GHQ 28):}

The GHQ-28 was developed by Goldberg in 1978. Since then it is translated into many languages. It was developed as a screening tool for detecting those likely to have or to be at risk of developing mental illnesses. It is a 28-item measure of emotional distress. It is divided into four subscales namely, somatic symptoms (items 1-7); anxiety/insomnia (items 8-14); social dysfunction (items 15-21), and severe depression (items 22-28).[19] It can be completed in less than 5 minutes.

\section{Instructions to subject and scoring:}

Examples of some of the items include 'Have you found everything getting on top of you?', 'Have you been getting scared or panicy for no good reason?', and 'Have you been getting edgy and bad tempered?' Each item is rated in four responses: Not at all, No more than usual, Rather more than usual, and Much more than usual. There are different scoring methods of GHQ-28. In Likert method, it is scored from 0 to 3 for each response with a total score ranging from 0 to 84 . In this method, a total score of 23/24 means there is distress. On the other hand, the GHQ-28 is also scored with a binary method where Not at all, and No more than usual score means 0 , and Rather more than usual and Much more than usual score means 1. In this method, score above 4 means there is distress. In our study, we have used binary method of scoring. Large number of studies have found out the reliability and validity of the GHQ-28 in various populations. Testretest reliability is reported to be high. The GHQ-28 correlates well with other scales of depression.[20]

\section{During the study period, the following parameters were estimated:}

Data was collected and tabulated using Microsoft excel.

1] Frequency and percentages calculated for all quantitative measures

2] Mean and standard deviation were calculated for qualitative measures.

3] Chi- square test was used to analyze categorical values.

4] $\mathrm{P}$ value of $<0.05$ is considered as statistically significant.

\section{Statistical analysis:}

SPSS 11 was used to process the data. Descriptive analysis was done to study the frequency of students who with least score and highest score.

\section{RESULTS}

Total strength of students participated was 131 for GHQ and 128 students rated DASS 21 . The mean age of the respondents was 21 years. 42\%(54) were male and 58\%(74) were female student respondents. 


\section{Depression, Anxiety, Stress among College Students in Bagalkot: A College Based Study}

DASS 21: The overall prevalence of symptoms of depression, anxiety and stress were 83.6\%, 92.2\% and 71.1\% respectively. The mean scores for Depression, Anxiety and Stress as per DASS 21 in males were 20.04(SD-7.03), 20.7(SD-6.91) and 20.63(7.53) respectively. The mean scores for Depression, Anxiety and Stress as per DASS 21 in females were 17.29(SD-10.42), 15.58(SD-7.31) and 16.41(SD-8.23) respectively. Regarding the severity of the depressive symptoms, it was found that $16.4 \%, 21.1 \%, 28.1 \%, 18.0 \%$ were having clinical depression with mild, moderate, severe and extremely severe grades and $16.4 \%$ were found to be in normal range. With respect to anxiety symptoms, 5.5\%, 32.8\%, $17.2 \%, 36.7 \%$ were graded as mild, moderate, severe and extremely severe anxiety and mere $7.8 \%$ fell under normal range. With respect to stress, $21.9 \%$, 25\%, 21.9\%, 2.3\% fell in mild, moderate, severe and extremely severe stress whereas $28.9 \%$ were found to be in normal range. Among males, 49 out of 54 were found to have depressive symptoms making it to $90.7 \%$ among females, 58 out of 74 were found to be having depressive symptoms accounting to $78.4 \%$. 54 among 54 males and 64 among 74 females had anxiety symptoms and 43 among 54 males and 48 among 74 had stress among females.

GHQ 28: The mean GHQ-28 scores for males and females were $6.44(\mathrm{SD}=4.64)$ \& 5.5 $(\mathrm{SD}=4.54)$ respectively. The least one has scored was zero and maximum score was 25.

Among 55 males, 40 had emotional distress (72.7\%) and 50 among 76 females (65.8\%) had significant emotional distress corresponding to 90 among 131 total students (68.7\%). 27.3\% males and 34\% females didn’t have significant emotional distress.

\section{DISCUSSION}

The GHQ-28 and DASS-21 are widely used scales to measure psychological health. These scales have been tested and validated in multiple languages. As found in our study, other studies also show that these scales have a good internal consistency. Our study results indicate high degree of depression, anxiety and stress among degree college students. This indicates the amount of burden students have to bear in the current scenario. It is necessary for students to be in their better psychological health so as to achieve success and for a brighter future.

In a study done in Malaysia, it was found a total of $41.9 \%$ of the medical students were having emotional disorders.[21] Stress can occur because of variety of factors like social adjustment to the environment, assignments, peer relationship, peer pressure to secure a high marks in exams. The ability to adapt to stress depends on the individual coping strategies. Overexposure to stress can lead to physical, emotional and mental health problems.[22] In another study, it was found that the prevalence of emotional disorders among students was very high. The study reported that there was significant association between emotional disorders and students relationship with their parents, siblings and lecturers, as well as level of pressure prior to exam. It is essential to search emotional disorders at an early stage so as to offer treatment to those who are affected.[23]

(C) The International Journal of Indian Psychology, ISSN 2348-5396 (e) | ISSN: 2349-3429 (p) | 183 
In our study as depicted in Table 2 and Table 3, 60.9\% (78 out of 128), $65.6 \%$ (84out of 128) respectively, who reported of emotional distress as per GHQ have shown to have varying degrees of symptoms of depression and anxiety as in DASS 21.

Table 1: Severity of depression, anxiety and stress on DASS-21

\begin{tabular}{|l|l|l|l|}
\hline Rating & Depression & Anxiety & Stress \\
\hline Normal & $0-9$ & $0-7$ & $0-14$ \\
\hline Mild & $10-13$ & $8-9$ & $15-18$ \\
\hline Moderate & $14-20$ & $10-14$ & $19-25$ \\
\hline Severe & $21-27$ & $15-19$ & $26-33$ \\
\hline Extremely Severely & $28^{+}$ & $20+$ & $37+$ \\
\hline
\end{tabular}

Table 2: Depression severity in DASS correlation with GHQ

\begin{tabular}{|c|c|c|c|c|}
\hline \multicolumn{2}{|c|}{ D Severity } & \multicolumn{2}{c|}{ GHQ Result } & \multirow{2}{*}{ Total } \\
\cline { 3 - 4 } \multicolumn{2}{c|}{} & $\begin{array}{c}\text { Distress- } \\
\text { Present }\end{array}$ & Distress-Absent & \\
\hline Normal & $\begin{array}{c}\text { Count } \\
\text { \% within GHQ result }\end{array}$ & 10 & $11 \%$ & 21 \\
& Count & 10 & $11 \%$ & $16.4 \%$ \\
\hline Mild & \% within GHQ result & $11.4 \%$ & $27.5 \%$ & $16.4 \%$ \\
\hline Moderate & Count & 20 & 07 & 27 \\
& \% within GHQ result & $22.7 \%$ & $17.5 \%$ & $21.1 \%$ \\
\hline Severe & Count & 26 & 10 & 36 \\
& \% within GHQ result & $29.5 \%$ & $25.0 \%$ & $28.1 \%$ \\
\hline Extremely & Count & 22 & 01 & 23 \\
Severe & \% within GHQ result & $25.0 \%$ & $2.5 \%$ & $18.0 \%$ \\
\hline Total & Count & 88 & 40 & 128 \\
& \% within GHQ result & $100.0 \%$ & $100.0 \%$ & $100 \%$ \\
\hline
\end{tabular}

Table 3: Anxiety severity in DASS correlation with GHQ

\begin{tabular}{|c|c|c|c|c|}
\hline \multicolumn{2}{|c|}{ A Severity } & \multicolumn{2}{|c|}{ GHQ Result } & \multirow[t]{2}{*}{ Total } \\
\hline & & $\begin{array}{c}\text { Distress- } \\
\text { Present } \\
\end{array}$ & Distress-Absent & \\
\hline Normal & $\begin{array}{c}\text { Count } \\
\text { \% within GHQ result }\end{array}$ & $\begin{array}{c}04 \\
4.5 \% \\
\end{array}$ & $\begin{array}{c}06 \\
15.0 \% \\
\end{array}$ & $\begin{array}{c}10 \\
7.8 \% \\
\end{array}$ \\
\hline Mild & $\begin{array}{c}\text { Count } \\
\text { \% within GHQ result }\end{array}$ & $\begin{array}{c}03 \\
3.4 \%\end{array}$ & $\begin{array}{c}04 \\
10.0 \%\end{array}$ & $\begin{array}{c}07 \\
5.5 \%\end{array}$ \\
\hline Moderate & $\begin{array}{c}\text { Count } \\
\text { \% within GHQ result }\end{array}$ & $\begin{array}{c}31 \\
35.2 \% \\
\end{array}$ & $\begin{array}{c}11 \\
27.5 \%\end{array}$ & $\begin{array}{c}42 \\
32.8 \% \\
\end{array}$ \\
\hline Severe & $\begin{array}{c}\text { Count } \\
\text { \% within GHQ result }\end{array}$ & $\begin{array}{c}17 \\
19.3 \%\end{array}$ & $\begin{array}{c}5 \\
12.5 \%\end{array}$ & $\begin{array}{c}22 \\
17.2 \%\end{array}$ \\
\hline $\begin{array}{l}\text { Extremely } \\
\text { Severe }\end{array}$ & $\begin{array}{c}\text { Count } \\
\text { \% within GHQ result }\end{array}$ & $\begin{array}{c}33 \\
37.5 \% \\
\end{array}$ & $\begin{array}{c}14 \\
35.0 \% \\
\end{array}$ & $\begin{array}{c}47 \\
36.7 \% \\
\end{array}$ \\
\hline Total & $\begin{array}{c}\text { Count } \\
\text { \% within GHQ result }\end{array}$ & $\begin{array}{c}88 \\
100.0 \%\end{array}$ & $\begin{array}{c}40 \\
100.0 \%\end{array}$ & $\begin{array}{c}128 \\
100 \%\end{array}$ \\
\hline
\end{tabular}

(c) The International Journal of Indian Psychology, ISSN 2348-5396 (e)| ISSN: 2349-3429 (p) | 184 


\section{CONCLUSION}

Early interventions are the need of the hour to improve the quality of life and reduce the stress among students. Multiple factors like feeling of incompetence, lack of motivation to learn and difficulty of class work might act as sources of the stressors that may precipitate depression, anxiety and stress. We can help the students to overcome their difficulties in their academic life by enhancing the mentor/mentee programs and implement them on regular basis. We need to discuss in detail the students' problems which will help them to release the tension applied on them so as to motivate them to give a better effort in their study. Constant watch should be on frequency and difficulty of the tests that are given to students so that the students are not overburdened which may exhaust them physically and mentally. We want to conclude by saying that emotional disturbances in the form of depression, anxiety and stress are existing in high rate among undergraduate science students that require early intervention.

\section{Acknowledgements:}

We wish to extend our sincere gratitude to all the participating students for their valuable time and responses for this study, irrespective of their busy schedule and the stigma attached to the issue. We thank the college authorities for their kindness of giving permission to conduct this study and for their cooperation.

Conflict of Interest: None declared

Source of Support: Nil

Abbreviations: GHQ-General Health Questionnaire, DASS-Depression, Anxiety and Stress Scale, SD-Standard Deviation, SPSS-Statistical Package for Social Studies

\section{REFERENCES}

1. Kumaraswamy N. Academic stress, anxiety and depression among college students- A brief review. International Review of Social Sciences and Humanities. 2013;5(1):135-43

2. Giugliano RJ. The systemic neglect of New York's young adults with mental illness. Psychiatr Serv. 2004;55(4):451-3.

3. Andrews B, Wilding JM. The relation of depression and anxiety to life-stress and achievement in students. Br J Psychol. 2004;95:509-21.

4. Emslie GJ, Mayes TL, Ruberu M. Continuation and maintenance therapy of early-onset major depressive disorder. Paediatr Drugs. 2005;7:203-17.

5. Kulsoom B, Afsar NA. Stress, anxiety, and depression among medical students in a multiethnic setting. Neuropsychiatr Dis Treat. 2015;11:1713-22.

6. Angst J, Preisig M. Course of a clinical cohort of unipolar, bipolar and schizoaffective patients. Results of a prospective study from 1959 to 1985. Schweiz Arch Neurol Psychiatr. 1995;146:5-16

7. Saipanish R. Stress among medical students in a Thai medical school. Med Teach. 2003;25(5):502-6 
8. Vitaliano PP, Russo J, Carr J E \& Heerwagen JH. Medical school pressures and their relationship to anxiety. J Nerv Ment Dis. 1984;172(12):730-6

9. Ko SM, Kua EH, Fones CSL. Stress and the Undergraduates. Singapore Med J. 1999; 40(10): 627-30.

10. Tyssen R, Vaglum P, Gronvold NT, Ekeberg O. Suicidal ideation among medical students and young physicians: a nationwide and prospective study of prevalence and predictors. $\mathrm{J}$ Affect Disord. 2001; 64(1): 6979

11. Kessler RC, Avenevoli S, Ries Merikangas K. Mood disorders in children and adolescents: An epidemiologic perspective. Biol Psychiatry. 2001;49:1002-14.

12. Hankin BL, Abramson LY, Moffitt TE, Silva PA, McGee R, Angell KE. Development of depression from preadolescence to young adulthood: Emerging gender differences in a 10year longitudinal study. J Abnorm Psychol. 1998; 107:128-40.

13. Goodman R. A modified version of the Rutter parent Questionnaire including extra items on children's strengths: A research note. J Child Psychol Psychiatry. 1994; 35:1483-94.

14. Sharif F, Armitage P. The effect of psychological and educational counselling in reducing anxiety in nursing students. J Psychiatr Ment Health Nurs. 2004;11:386-92.

15. Gao F, Luo N, Thumboo J, Fones C, Li SC, Cheung YB. Does the 12-item General Health Questionnaire contain multiple factors and do we need them? Health Qual Life Outcomes. 2004;2:63.

16. Goldberg D, Williams P. A user's guide to the General Health Questionnaire. Slough: NFERNelson; 1988.

17. Goldberg DP, Gater R, Sartorius N, Ustun TB, Piccinelli M, Gureje O , \& Rutter C. The validity of two versions of the GHQ in the WHO study of mental illness in general health care. Psychol Med. 1997; 27(1): 191-7.

18. Lovibond SH, Lovibond PF. Manual for the Depression Anxiety Stress Scales. Sydney: Psychology Foundation. 1995; 2nd. Edn

19. Goldberg D. Manual of the General Health Questionnaire. Windsor: NFER-Nelson. 1978

20. Robinson RG, Price T. Post-stroke depressive disorders: a follow-up study of 103 patients. Stroke. 1982;13: 635.

21. Salam A, Yousuf R, Bakar SMA, Haque M. Stress among Medical Students in Malaysia: A Systematic Review of Literatures. International Medical Journal. 2013; 20 (6): 649 - 55.

22. Niemi PM \& Vainiomäki P. T. Medical Students’ Academic Distress, Coping, and Achievement Strategies During the Preclinical Years. Teach Learn Med. 1999;11:125-34.

23. Zaid ZA, Chan SC \& Ho JJ. Emotional disorders among medical students in a Malaysian private medical school. Singapore Med J. 2007; 48(10): 895-99

How to cite this article: N Mutalik, S Moni, S Choudhari, G Bhogale (2016), Depression, Anxiety, Stress among College Students in Bagalkot: A College Based Study, International Journal of Indian Psychology, Volume 3, Issue 4, No. 68, ISSN:2348-5396 (e), ISSN:2349-3429 (p), DIP:18.01.210/20160304, ISBN:978-1-365-39398-3 